\title{
Note on Intra-supply Chain System with an Improved Distribution Plan, Multiple Sales Locations and Quality Assurance
}

\author{
Tsu-Ming Yeh" ${ }^{*}$, Fan-Yun Pai ${ }^{2}$ \\ ${ }^{1}$ Department of Industrial Engineering and Management, Quemoy University, No. 1, University Rd., Jinning \\ Township, Kinmen County 892, Taiwan. \\ ${ }^{2}$ Department of Business Administration, National Changhua University of Education, No.2, Shi-Da Road, \\ Changhua City, 500, Taiwan.
}

* Corresponding author. Tel.: 886-932639314; email: tmyeh@mail.dyu.edu.tw

Manuscript submitted March 6, 2017; accepted August 5, 2017.

doi: 10.17706/ijeeee.2018.8.1.10-17

\begin{abstract}
Prior studies used the mathematical model along with differential calculus to examine an intra-supply chain system with an improved distribution plan, multiple sales locations and quality assurance. In this paper, we propose an alternative approach to the problem and demonstrate that optimal operating decision to this specific intra-supply chain problem can be determined by the proposed simplified method without derivatives.
\end{abstract}

Key words: Optimization, replenishment lot size, delivery plan, multiple sales locations.

\section{Introduction}

An intra-supply chain system with multiple sales locations and quality assurance was explored by Chiu et al. [1]. They considered a manufacturer firm owns several regional sales offices for distribution of end products that made by its single production unit. Quality assurance matters in their study included screening of all items in production process, the reworking of defective items, and scrapping failure-in-rework items. In each production cycle, after rework a multi-delivery plan was employed to transport finished end items to various regional sales locations simultaneously. Their objective was to simultaneously determine the optimal replenishment batch size and the optimal number of shipments that minimize the long-run average system cost for such an intra- supply chain system. The aforementioned study was extended by Chiu et al. [2] wherein an improved $(n+1)$ distribution plan was incorporated with the aim of reducing inventory holding costs for both the manufacturing unit and regional sales offices. Conventional mathematical modeling along with differential calculus approach was utilized by both studies to derive their operating decisions. Additional studies that addressed various aspects of multi-shipment, multi-customers, quality assurance, and supply chains systems can be referred to [3]-[10].

Grubbström and Erdem [11] proposed an unconventional algebraic approach to solve the economic order quantity (EOQ) model with backlogging without using the derivatives (neither first- nor second-order differentiations). Several studies employed such an approach to resolve a variety of particular replenishment batch size and supply chains problems [12]-[14]. This paper applies this unconventional algebraic approach to the problem presented by Chiu et al. [2] and shows the same optimal operating 
decision can be obtained without using derivatives.

\section{Problem and the Proposed Approach}

To relieve comparison efforts for readers, we reexamine the intra-supply chain problem [2] with the same notation they used. Description of their intra-supply chain system is as follows. A manufacturer firm owns a few regional sales offices for distribution of end products made by its single production unit. The product can be fabricated at an annual rate $\mathrm{P}$ and there is an x portion of random defective rate associated with the production process. Hence, production rate of defective items $d$ can be expressed as $d=P x$. All items produced are screened for the quality purpose and the inspection cost in included in unit manufacturing cost C. Defective items are reworked right after the regular production process in each cycle at a rate of P1. There exists a rate of failure in rework $\theta 1$ and these defective items are scrapped. Under the improved $(\mathrm{n}+$ 1) distribution plan, in production uptime an initial shipment of finished products is transported to multiple sales locations to meet customer's demand during the production unit's uptime and rework time (Figure 1). Then, upon completion of the rework process, $n$ fixed quantity installments of the end products are delivered at a fixed time interval to sales locations. Fig. 1 illustrates the on-hand inventory level of finished products in the production cycle [2].

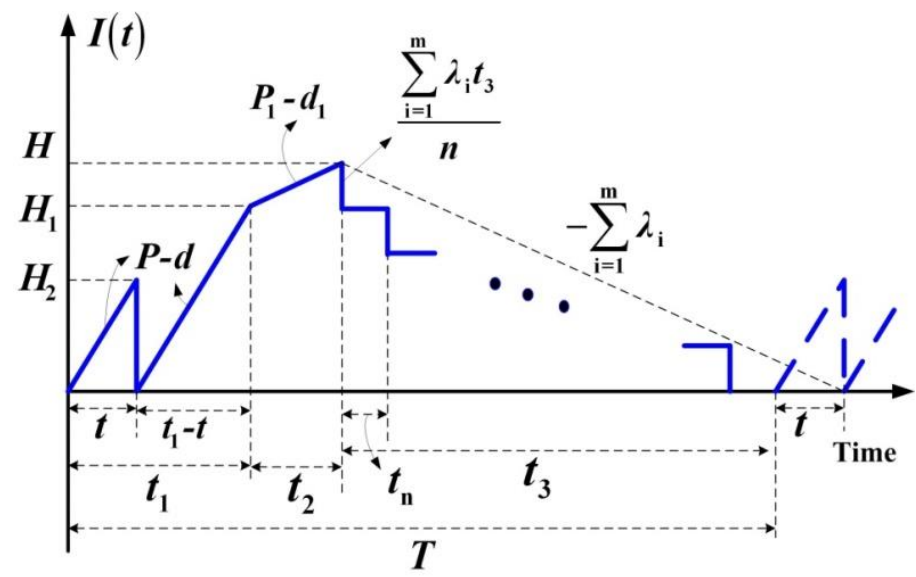

Fig. 1. The on-hand inventory level of finished products in a production cycle.

To avoid occurrence of shortages, a prerequisite assumption is that the production rate $P$ must satisfy $(P$ $d-\lambda$ ) $>0$, where $\lambda$ is the sum of the customer's demands (i.e., the sum of $\lambda_{i}$ ). Fig. 2 depicts the on-hand stock levels at the regional sales offices [2].

Additional notation used in the proposed system also includes the following:

$K=$ production setup cost,

$H=$ unit holding cost,

$C_{\mathrm{R}}=$ unit reworking cost,

$h_{1}=$ unit holding cost for reworked items,

$\theta_{1}=$ failure in rework rate,

$C_{\mathrm{S}}=$ unit disposal cost for failure in rework items,

$K_{1 i}=$ fixed delivery cost per shipment transported to regional sales office $i$,

$C_{\mathrm{Ti}}=$ unit delivery cost for items transported to regional sales office $i$,

$h_{2 i}=$ unit holding cost for stocks stored at regional sales offices $i$,

$T=$ production cycle length,

$t_{1}=$ production uptime, 
$t_{2}=$ reworking time,

$t_{3}=$ production downtime,

$Q=$ batch size,

$n=$ number of shipments,

$H_{2}=$ level of finished items to meet demands during $t_{1}$ and $t_{2}$,

$H_{1}=$ level of on-hand inventory when production process ends,

$H=$ level of on-hand inventory when rework process ends,

$t_{\mathrm{n}}=\mathrm{a}$ fixed interval of time between each installment of end products delivered in $t_{3}$,

$m=$ number of regional sales offices,

$I(t)=$ the level of on-hand inventory of perfect quality items at time $t$,

$I_{\mathrm{c}}(t)=$ the level of sales offices' on-hand inventory at time $t$,

$D_{\mathrm{i}}=$ number of finished items being distributed to sales office $i$ per delivery,

$I_{\mathrm{i}}=$ number of leftover items in sales office $i$ after the depletion during $t_{n}$,

$T C(Q, n+1)=$ total system cost per cycle for the proposed $n+1$ delivery model,

$\mathrm{E}[\operatorname{TCU}(Q, n+1)]=$ the expected total production-inventory-delivery costs per unit time for the proposed $n+1$ delivery model.
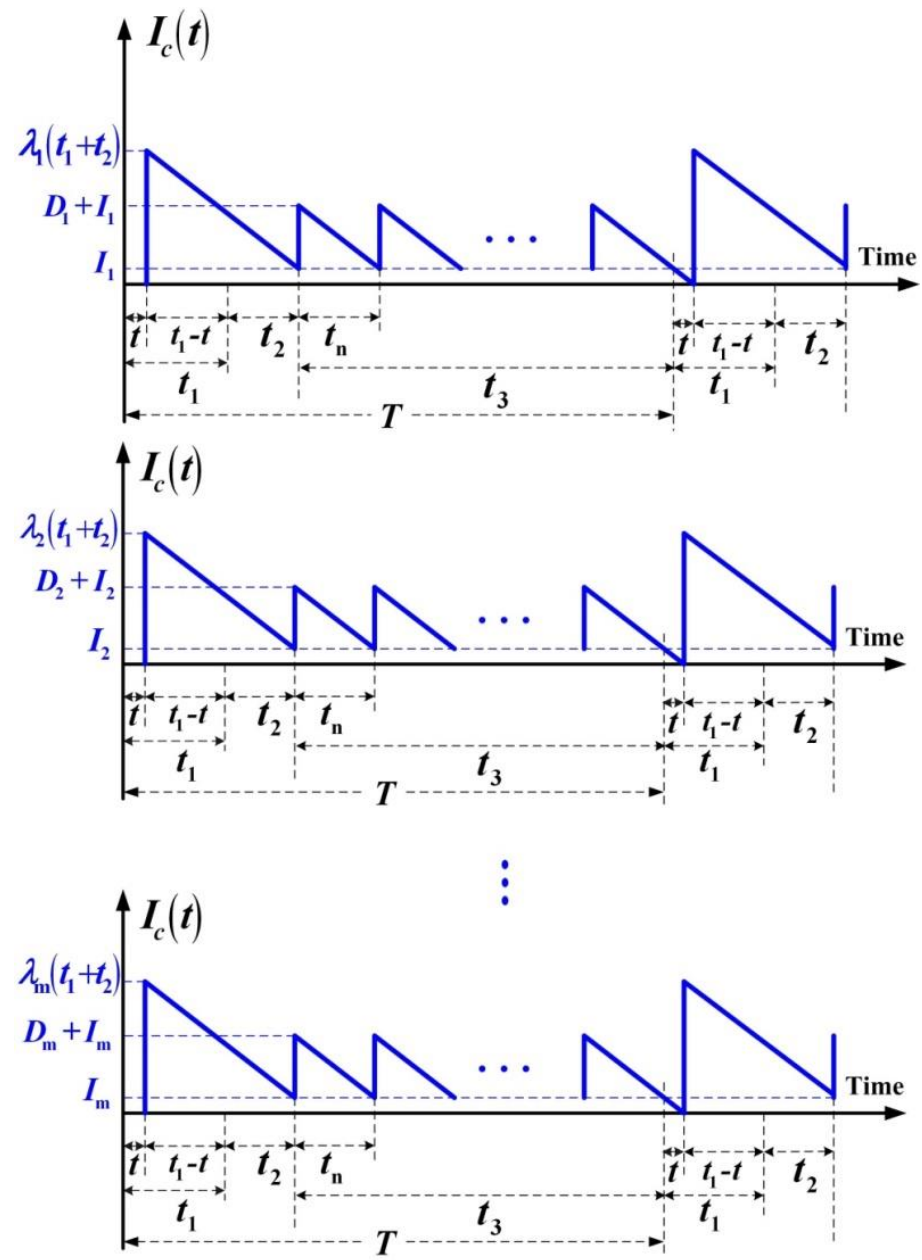

Fig. 2. The on-hand stock levels at the regional sales offices.

Recall $E[T C U(Q, n+1)]$ the expected total production-inventory-delivery costs per unit time for the proposed intra-supply chain system [2] as follows: 


$$
\begin{aligned}
E & {[T C U(Q, n+1)]=C \lambda E_{3}+\frac{K \lambda}{Q} E_{3}+C_{R} \lambda E_{4}+C_{s} \theta_{1} \lambda E_{4}+\sum_{i=1}^{m} C_{T_{i}} \lambda_{i}+\frac{h_{1} Q \lambda}{2 P_{1}} E_{5} } \\
& +\frac{(n+1) \lambda E_{3}}{Q} \sum_{i=1}^{m} K_{1 i}+h Q \lambda\left\{\begin{array}{l}
\frac{\lambda^{2} E_{0}}{P^{3}}+\frac{2 \lambda^{2} E_{1}}{P^{2} P_{1}}+\frac{\lambda^{2} E_{2}}{P P_{1}^{2}}-\frac{\lambda E_{3}}{2 P^{2}}-\frac{\lambda E_{4}}{P P_{1}}+\frac{1}{2 E_{3} \lambda} \\
-\frac{\left(1-2 \theta_{1} E[x]\right) E_{3}}{2 P}-\frac{1}{2 P_{1}}\left[1+\frac{\lambda}{P_{1}}-\theta_{1}\right] E_{5}
\end{array}\right\} \\
& +\sum_{i=1}^{m} h_{2 i} Q \lambda_{i}\left\{-\frac{\lambda^{2} E_{0}}{P^{3}}-\frac{2 \lambda^{2} E_{1}}{P^{2} P_{1}}-\frac{\lambda^{2} E_{2}}{P P_{1}^{2}}+\frac{\lambda E_{3}}{2 P^{2}}+\frac{\lambda E_{4}}{P P_{1}}+\frac{\lambda E_{5}}{2 P_{1}^{2}}+\frac{\lambda E_{6}}{P^{2}}+\frac{\lambda E_{7}}{P P_{1}}\right\} \\
& +\left(\frac{Q}{n}\right)\left\{\frac{1}{2 \lambda E_{3}}-\frac{1}{P}-\frac{E[x]}{P_{1}}+\frac{\lambda E_{3}}{2 P^{2}}+\frac{\lambda E_{4}}{P P_{1}}+\frac{\lambda E_{5}}{2 P_{1}^{2}}\right\}\left[\left(\sum_{i=1}^{m} h_{2 i} \lambda_{i}\right)-h \lambda\right]
\end{aligned}
$$

where $E_{\mathrm{i}}$ denotes the following:

$$
\begin{aligned}
& E_{0}=E\left(\frac{1}{1-x}\right) E_{3} ; E_{1}=E\left(\frac{x}{1-x}\right) E_{3} ; E_{2}=E\left(\frac{x^{2}}{1-x}\right) E_{3} ; E_{3}=\frac{1}{1-\theta_{1} E[x]} \\
& E_{4}=E[x] E_{3} \quad ; \quad E_{5}=(E[x])^{2} E_{3} ; E_{6}=E\left(\frac{1}{1-x}\right) \quad ; \quad E_{7}=E\left(\frac{x}{1-x}\right)
\end{aligned}
$$

Apply the unconventional algebraic approach [11] to $E[\operatorname{TCU}(Q, n+1)]$, we rearrange Eq. (1) as

$$
E[T C U(Q, n+1)]=z_{1}+z_{2} Q^{-1}+z_{4} Q+z_{3}\left(n Q^{-1}\right)+z_{5}\left(Q n^{-1}\right)
$$

where $z_{\mathrm{i}}$ denotes the following:

$$
\begin{gathered}
z_{1}=C \lambda E_{3}+C_{R} \lambda E_{4}+C_{S} \theta_{1} \lambda E_{4}+\sum_{i=1}^{m} C_{T i} \lambda_{i} \\
z_{2}=\lambda E_{3}\left(K+\sum_{i=1}^{m} K_{1 i}\right) \\
z_{3}=\lambda E_{3} \sum_{i=1}^{m} K_{1 i} \\
z_{4}=h \lambda\left\{\frac{\lambda^{2} E_{0}}{P^{3}}+\frac{2 \lambda^{2} E_{1}}{P^{2} P_{1}}+\frac{\lambda^{2} E_{2}}{P P_{1}^{2}}-\frac{\lambda E_{3}}{2 P^{2}}-\frac{\lambda E_{4}}{P P_{1}}-\frac{\left(1-2 \theta_{1} E[x]\right) E_{3}}{2 P}+\frac{1}{2 E_{3} \lambda}-\frac{1}{2 P_{1}}\left[1+\frac{\lambda}{P_{1}}-\theta_{1}\right] E_{5}\right\} \\
+\frac{h_{1} \lambda}{2 P_{1}} E_{5}+\sum_{i=1}^{m} h_{2 i} \lambda_{i}\left\{-\frac{\lambda^{2} E_{0}}{P^{3}}-\frac{2 \lambda^{2} E_{1}}{P^{2} P_{1}}-\frac{\lambda^{2} E_{2}}{P P_{1}^{2}}+\frac{\lambda E_{3}}{2 P^{2}}+\frac{\lambda E_{4}}{P P_{1}}+\frac{\lambda E_{5}}{2 P_{1}^{2}}+\frac{\lambda E_{6}}{P^{2}}+\frac{\lambda E_{7}}{P P_{1}}\right\} \\
z_{5}=\left\{\frac{1}{2 \lambda E_{3}}-\frac{1}{P}-\frac{E[x]}{P_{1}}+\frac{\lambda E_{3}}{2 P^{2}}+\frac{\lambda E_{4}}{P P_{1}}+\frac{\lambda E_{5}}{2 P_{1}^{2}}\right\}\left[\left(\sum_{i=1}^{m} h_{2 i} \lambda_{i}\right)-h \lambda\right]
\end{gathered}
$$

Eq. (2) can now be rearranged as 


$$
E[\operatorname{TCU}(Q, n+1)]=z_{1}+Q^{-1}\left(z_{2}+z_{4} Q^{2}\right)+\left(n Q^{-1}\right)\left[z_{3}+z_{5}\left(Q n^{-1}\right)^{2}\right]
$$

Further rearrangement we have

$$
\begin{aligned}
E[T C U(Q, n+1)] & =z_{1}+\left(\sqrt{z_{2}}-\sqrt{z_{4}} Q\right)^{2} Q^{-1}+\left[\sqrt{z_{3}}-\sqrt{z_{5}}\left(Q n^{-1}\right)\right]^{2}\left(n Q^{-1}\right) \\
& +2 \sqrt{z_{2}} \sqrt{z_{4}}+2 \sqrt{z_{3}} \sqrt{z_{5}}
\end{aligned}
$$

It is noted that if the second and third terms in the right-hand side (RHS) of Eq. (9) both equal zero, then $\mathrm{E}[\operatorname{TCU}(Q, n+1)]$ can be minimized. Therefore, we have

$$
Q=\sqrt{\frac{z_{2}}{z_{4}}} \text { and } n=Q \sqrt{\frac{z_{5}}{z_{3}}}
$$

or

$$
n=\sqrt{\frac{z_{2} z_{5}}{z_{4} z_{3}}}
$$

Substitute equations (4) to (7) in Eq. (11), the optimal number of shipments are obtained as follows:

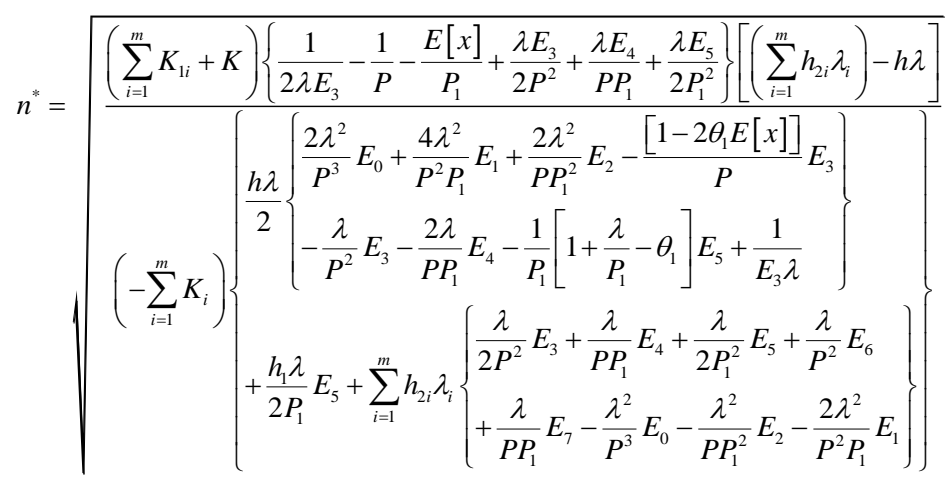

It is noted that Eq. (12) is identical to that in Chiu et al. [2]. As indicated in Chiu et al. [1] that in real world situation the number of shipment can only be integer. Therefore, the same procedure suggested in Chiu et al. [1] must apply to locate the integer value of $n$ that minimizes the long-run expected system costs. Upon completion of obtaining $n$ we rearrange Eq. (2) to determine the optimal replenishment batch size as follows:

$$
E[\operatorname{TCU}(Q, n+1)]=z_{1}+Q^{-1}\left(z_{2}+n z_{3}\right)+Q\left(z_{4}+n^{-1} z_{5}\right)
$$

Further rearrangement we have

$$
E[\operatorname{TCU}(Q, n+1)]=z_{1}+Q^{-1}\left[\left(z_{2}+n z_{3}\right)+\left(z_{4}+n^{-1} z_{5}\right) Q^{2}\right]
$$


or

$$
E[T C U(Q, n+1)]=z_{1}+Q^{-1}\left[\left(\sqrt{z_{2}+n z_{3}}\right)-\left(\sqrt{z_{4}+n^{-1} z_{5}}\right) Q\right]^{2}+2 \sqrt{z_{2}+n z_{3}} \sqrt{z_{4}+n^{-1} z_{5}}
$$

It is noted that if the second term in the RHS of Eq. (15) equals zero, then $\mathrm{E}[T C U(Q, n+1)]$ can be minimized. Therefore, we have

$$
Q=\frac{\sqrt{z_{2}+n z_{3}}}{\sqrt{z_{4}+n^{-1} z_{5}}}
$$

Substitute equations (4) to (7) in Eq. (16), optimal replenishment batch size $Q^{*}$ is obtained as follows:

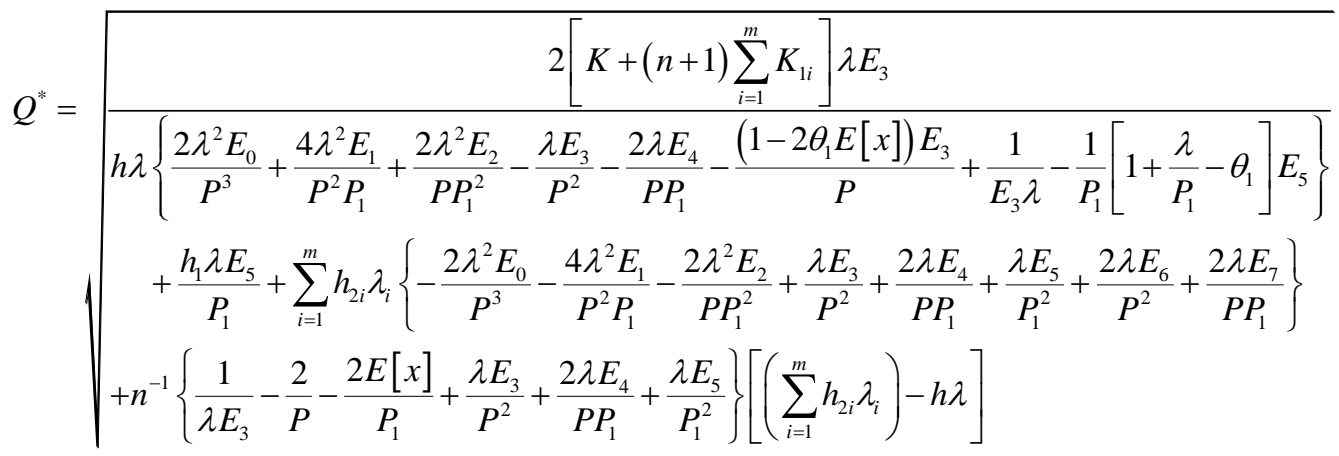

It is noted that Eq. (17) is identical to that in Chiu et al. [2]. From Eq. (15), we also reveal the following simplified form for optimal $\mathrm{E}[\operatorname{TCU}(Q, n+1)]$ :

$$
E[\operatorname{TCU}(Q, n+1)]=z_{1}+2 \sqrt{z_{2}+n z_{3}} \sqrt{z_{4}+n^{-1} z_{5}}
$$

\section{Numerical Demonstration}

To ease comparison efforts for readers, in this subsection we use the same numerical example as in Chiu et al. [1] to demonstrate the practical use of the obtained results. The values of relevant parameters used are listed below:

$\mathrm{P}=60,000$ units per year,

$i=1,2, \ldots$, and 5 , denotes five different regional sales locations,

$\lambda i=400,500,600,700$, and 800 units per year, respectively (i.e., $\operatorname{sum} \lambda=3000$ ),

$\mathrm{xi}=$ follows a Uniform distribution over the interval $[0,0.3]$,

$\mathrm{K}=\$ 35,000$ per cycle,

$\mathrm{C}=\$ 100$ per item,

$\mathrm{H}=\$ 25$ per item,

$\mathrm{P} 1=3600$ units per year,

$\mathrm{CR}=\$ 60$ per reworked item,

h1 $=\$ 60$ per reworked item per unit time, 
$\theta 1=0.2$ the failure in rework rate,

$\mathrm{CS}=\$ 20$ per scrap item,

$\mathrm{K} 1 \mathrm{i}=\$ 100, \$ 200, \$ 300, \$ 400$ and $\$ 500$, respectively,

$\mathrm{CTi}=\$ 0.5, \$ 0.4, \$ 0.3, \$ 0.2$, and $\$ 0.1$, respectively,

$\mathrm{h} 2 \mathrm{i}=\$ 75, \$ 70, \$ 65, \$ 60$, and $\$ 55$, respectively.

Apply Eq. (12), we obtain $n=5.272$. By examining two adjacent integers to $n$ and substitute them into Eq. (17), we found $(Q, n-+1)=(2885,6)$ and $(Q, n++1)=(2980,7)$. Apply these production-shipment policies in Eq. (2), and then select the one with less expected system cost as our optimal operating decision. Thus, optimal policy $\left(Q^{*}, n^{*}+1\right)=(2885,6)$ is determined, and its associated optimal system costs $E\left[T C U\left(Q^{*}, n^{*}+\right.\right.$ $1)]=\$ 434,009$. It is noted that these results are identical to that in Chiu et al. [2]. Further analytical results with regard to the performance and advantage of this specific intra-supply chain system can be referred to sections 3 and 4 of Chiu et al. [2].

\section{Conclusion}

This paper applies an unconventional algebraic approach [11] to the intra-supply chain problem presented by Chiu et al. [2] and successfully demonstrates that the optimal operating decisions to the problem can be derived without using derivatives. Such a straightforward algebraic derivation may help practitioners or anyone who with insufficient knowledge of calculus better understand and manage the real intra-supply chain systems.

\section{References}

[1] Chiu, S. W., Lee, C. H., Chiu, Y. S., \& Cheng, F. T. (2013). Intra-supply chain system with multiple sales locations and quality assurance. Expert System with Application, 40(7), 2669-2676.

[2] Chiu, S. W., Huang, C. C., Chiang, K. W., \& Wu, M. F. (2015). On intra-supply chain system with an improved distribution plan, multiple sales locations and quality assurance. SpringerPlus, 4, 687-698.

[3] Khouja, M. (2003). Optimizing inventory decisions in a multi-stage multi-customer supply chain. Transport Res E-LOG, 39, 193-208.

[4] Benjaafar, S., \& Elhafsi, M. (2006). Production and inventory control of a single product assembleto-order system with multiple customer classes. Management Science, 52, 1896-1912.

[5] Ervolina, T. R., Ettl, M., Lee, Y. M., \& Peters, D. J. (2009). Managing product availability in an assemble-to-order supply chain with multiple customer segments. OR Spectrum, 31, 257-280.

[6] Glock, C. H. Coordination of a production network with a single buyer and multiple vendors. International Journal of Production Economic, 135(2), 771-780.

[7] Chiu, Y. S., Chang, H. H. (2014). Optimal run time for EPQ model with scrap, rework and stochastic breakdowns: A note. Economic Modeling, 37, 143-148.

[8] Rodger, J. A. (2014). Application of a fuzzy feasibility bayesian probabilistic estimation of supply chain backorder aging, unfilled backorders, and customer wait time using stochastic simulation with Markov blankets. Expert System with Application, 41, 7005-7022.

[9] Lin, G. C., Gong, D. C., \& Chang, C. C. (2014). On an economic production quantity model with two unreliable key components subject to random failures. Journal of Scientific and Industrial Research, 73(3), 149-152.

[10] Safaei, M. (2014). An integrated multi-objective model for allocating the limited sources in a multiple multi-stage lean supply chain. Economic Modeling, 37, 224-237.

[11] Grubbström, R. W., \& Erdem. A. (1999). The EOQ with backlogging derived without derivatives. International Journal of Production Economic, 59, 529-530. 
[12] Lin, H. D., Chiu. Y. S., \& Ting. C. K. (2008). A note on optimal replenishment policy for imperfect quality EMQ model with rework and backlogging. Computers \& Mathematics with Applications, 56(11), 2819-2824.

[13] Chen, K. K., Wu, M. F., Chiu, S. W., \& Lee, C. H. (2012). Alternative approach for solving replenishment lot size problem with discontinuous issuing policy and rework. Expert System with Application, 39(2), 2232-2235.

[14] Tseng, C. T., Wu, M. F., Lin, H. D., \& Chiu, Y. S. (2014). Solving a vendor-buyer integrated problem with rework and a specific multi-delivery policy by a two-phase algebraic approach. Economic Modeling, 36, 30-36.

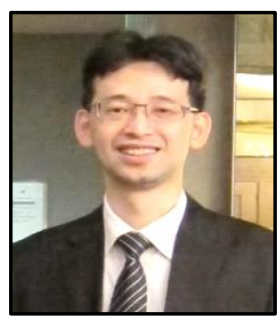

Tsu-Ming Yeh is professor of the Department of Industrial Engineering and Management at National Quemoy University, Taiwan. He received the Ph.D. degree from Department of Industrial Engineering in Chung-Yuan Christian University, Taiwan. His research interests include quality management, operation management, and service management.

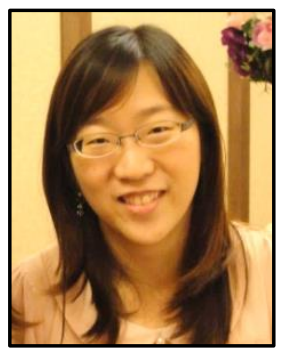

Fan-Yun Pai is professor of Dept. of Business Administration and received her $\mathrm{PhD}$ degree in Business Administration from National Taiwan University in 2008. Dr. Pai's research interests include service and operation management and supply chain management. She has published articles in expert systems with applications, industrial marketing management, technological forecasting and social change, International Journal of Production Research, Production Planning and Control, International Journal of Production Economics, Quality and Quantity, and the Service Industry Journal, etc. 